\title{
Frequency and Time Fault Diagnosis Methods of Power Transformers
}

\author{
Miroslav Gutten ${ }^{1}$, Daniel Korenciak ${ }^{1}$, Matej Kucera ${ }^{1}$, Richard Janura ${ }^{2}$, Adam Glowacz ${ }^{3}$, \\ Eliasz Kantoch ${ }^{4}$ \\ ${ }^{1}$ University of Žilina, Faculty of Electrical Engineering, Department of Measurement and Applied Electrical Engineering, \\ Univerzitná 1, 01026 Žilina, Slovak Republic, miroslav.gutten@fel.uniza.sk, daniel.korenciak@fel.uniza.sk, \\ matej.kucera@fel.uniza.sk \\ ${ }^{2}$ ČEZ, a. s., Nuclear Power Plant Temelin, 37305 Temelin CZ, Czech Republic, richard.janura@cez.cz \\ ${ }^{3}$ AGH University of Science and Technology, Faculty of Electrical Engineering, Automatics, Computer Science and \\ Biomedical Engineering, Department of Automatic Control and Robotics, \\ Al. A. Mickiewicza 30, 30-059 Kraków, Poland, adglow@agh.edu.pl \\ ${ }^{4}$ AGH University of Science and Technology, Faculty of Electrical Engineering, Automatics, Computer Science and \\ Biomedical Engineering, Department of Biocybernetics and Biomedical Engineering, Al. A. Mickiewicza 30, 30-059 \\ Kraków, Poland, kantoch@agh.edu.pl
}

\begin{abstract}
The authors describe experimental and theoretical analyses of faults of power transformer winding. Faults were caused by mechanical effect of short-circuit currents. Measurements of transformer were carried out in high-voltage laboratory. Frequency and time diagnostic methods (method SFRA - Sweep Frequency Response Analysis, impact test) were used for the analyses. Coils of transformer windings were diagnosed by means of the SFRA method and the time impact test. The analyzed methods had a significant sensitivity to a relatively small deformation of coil. In the analysis a new technique for analyzing the effects of short-circuit currents is introduced. This technique is developed for high-voltage transformers (different types of power). The proposed analyses show that it is necessary to analyze the value of short-circuit current. Short-circuit current represents a danger for the operation of the power transformer. The proposed approach can be used for other types of transformers. Moreover, the presented techniques have a potential application for fault diagnosis of electrical equipment such as: transformers and electrical machines.
\end{abstract}

Keywords: Fault, short-circuit, transformer, diagnostics, frequency.

\section{INTRODUCTION}

Maintenance diagnostics of short-circuit currents of transformers should be carried out to increase the reliability in real trouble-free process. The short-circuits in operation are commonly caused by different faults such as: mechanical damage of insulation, electric insulation breakdown (caused by voltage), over heating fault, or open circuit fault [1].

The short-circuit is a serious fault for the transformer. High electric currents can damage the device easily. Electric currents cause high temperature of windings therefore their isolation is damaged. However, high electro-magnetic forces are much more dangerous. Electro-magnetic forces can damage the transformer permanently.

It is necessary to pay attention to higher reliability of power transformers, due to possible failures of an electric system and because of their cost.
Windings of the power transformer should be designed to avoid mechanical and thermal faults caused by short-circuit currents. Permanent deformations and gradual aging process of the electrical device are often caused by short-circuit current. Gradual aging process can worsen its mechanical properties. Heat shocks often cause decrease of mechanical properties of the transformer. Next it can cause unexpected damage of transformer during its operation.

Vibration based fault diagnosis of transformer winding was presented in the literature [2]. Fault diagnosis of power transformers using dissolved gas analysis was presented in the literature [3]-[7]. Electrical parameters of transformers were analyzed [8]-[10]. Signal processing and classification methods were also used for proper fault diagnosis of transformers [11]-[14] and other types of machines [15][18]. 
To prevent the faulty state of transformers, the authors performed different types of diagnostic measurements. The measurements should illustrate a current state of the measured power transformer. It is essential to select a proper diagnostic method for the recognition of faulty state.

In the analysis a new technique for analyzing the effects of short-circuit currents is introduced. This technique is developed for high-voltage transformers (different types of power).

The authors focused on short-circuit of the transformer windings. The effect of magnetic field on conductor current causes the creation of forces. Mentioned forces have effect on coils of windings.

The electric currents of the transformer do not exceed rated values for normal operation. The electromagnetic forces effecting on transformer winding are low. The currents of short-circuits can reach the multiple of rated values of the transformer.

Then the forces can become dangerous for transformer coils of windings, electric and magnetic circuits, taps and the whole construction.

The short-circuit forces affecting on windings can be divided into two groups [19]:

$$
\text { - radial (cross), }
$$

Radial forces are caused by electromagnetic lengthwise fields. They act in the radial direction. Radial forces are generated by leakage flux density and the current. They are paralleled with the axis of transformer winding. Radial forces extend external high-voltage windings. They also compress internal low-voltage windings. For this reason, the air interspaces are bigger.

Axial forces act in the axial direction. Similar to radial forces, axial forces are generated by leakage flux density and the current. They are dangerous from the center to border of coil. In this area of transformer the magnetic field has the high value in up and down edge of winding. Axial forces can reach dangerous values of short-circuits forces. They can also deform the outer high-voltage coil [19].

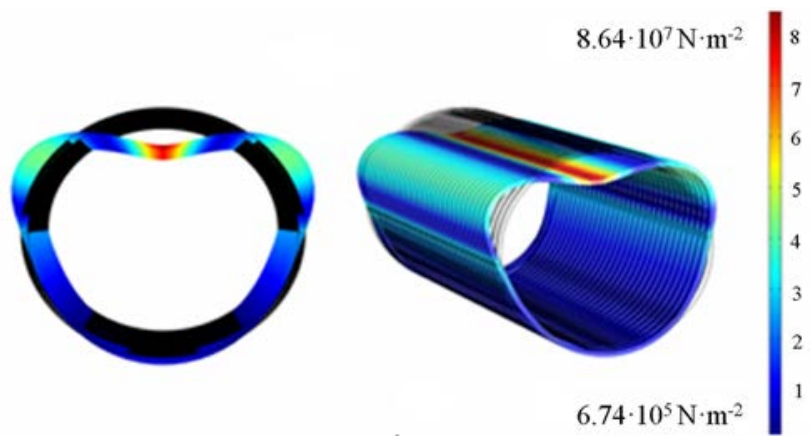

Fig.1. Simulation deformation of coil of the high-voltage winding $(22 \mathrm{kV})$.

According to the literature [19] it is required to pay more attention to catching the outer high-voltage coil of winding. In case of a loose coil, the short-circuit axial forces Fd result in a vertical shift of outer coils of winding. The excessive pressure on spacers can press on the coil insulation and shift the winding. It can also cause serious damage to the transformer windings.

Fig.1. shows the simulation deformation of coil of the high-voltage winding $(22 \mathrm{kV})$. It is influenced by radial forces (permanent shift of winding).

Fig.2. shows the simulation of pressure stress and permanent deformation of outer coil of winding. It was caused by short-circuit of the transformer. Axial forces are also proportional to the maximum current of the shortcircuit. Even with a little imbalance between the windings, this force can be increased.
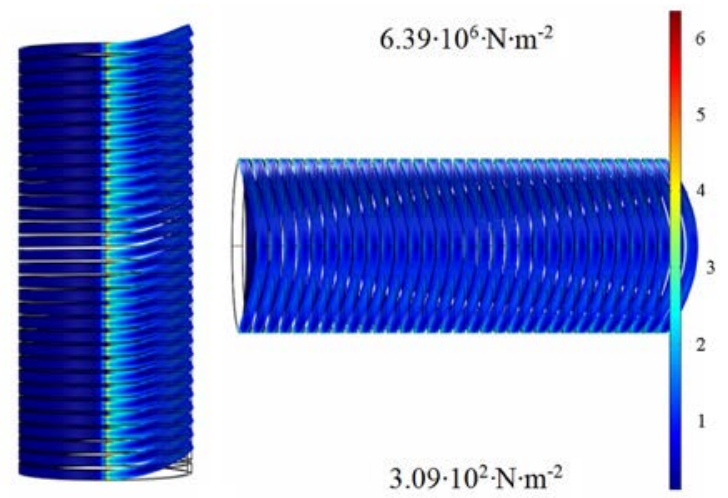

Fig.2. Permanent deformation of outer coil of winding. It was influenced by pressure stress from axial force ( $5 \%$ per unit imbalance of the windings).

Based on theoretical and simulating analysis it can be noticed that the analysis of dangerous short-circuit forces is essential. It is necessary to determine the possible effects of short-circuit. It can also change the insulating state and the mechanical state of transformer.

\section{EXPERIMENTAL DIAGNOSTIC METHODS OF TRANSFORMERS}

The main problem of current energy transmission and distribution is that the measured data from the diagnostic measurements are not analyzed so much. There are problems to find scientific databases of such signals. Therefore, it is problem to assess the technical state of power transformers depending on their residual lifetime. A fault can occur in an unpredictable time of operation. The result of this can be the power failure for a short or a long time. It is needed to analyze the measured and computed values of parameters. It is based on knowledge of exposure to adverse effects of specific electrical equipment.

Achieving objectives by using the measurements can help to explain the adverse effects of short-circuit and propose new diagnostic techniques. Moreover, it is possible to detect an approaching fault of the electric device. Some steps may be also proposed in advance (e.g. repair of transformer) [20], [21].

The authors consider the influence of overvoltage, switching currents, short-circuit forces. Following measurements can be carried out for analyzed power transformers: 
- measurements of transformer impedance depending on the frequency characteristics. It can be carried out using the SFRA method,

- time measurements of transformer coils. It can be carried out using impact test - high-voltage pulse source,

- measurements of impedance, resistivity of power transformer windings,

- $\quad$ analysis of the transformer oil,

- measurements of electric currents, voltages, insulation resistances using methods: RVM - Relevance Vector Machine, PDC - Polarization and Depolarization Current,

- measurements of loss factor and capacity,

- measurements of isolation parameters of the power transformer with application of dielectric spectroscopy,

- measurements of temperature of the transformer winding using FBG - Fiber Bragg Grating [22],

- $\quad$ selected variant of measuring methods.

Different measuring methods and diagnostic techniques can be used for fault diagnosis of transformers such as: analysis of acoustic emission, thermal images, electromagnetic radiation, analysis of temperature and moisture of transformers. The mentioned techniques can be used for detection of the effects of overvoltages and shortcircuits. Effects of overvoltages and short-circuits can damage coils of the transformer. Repair of power transformer costs time and money. Mentioned techniques can be applied for disconnected power transformer [23].

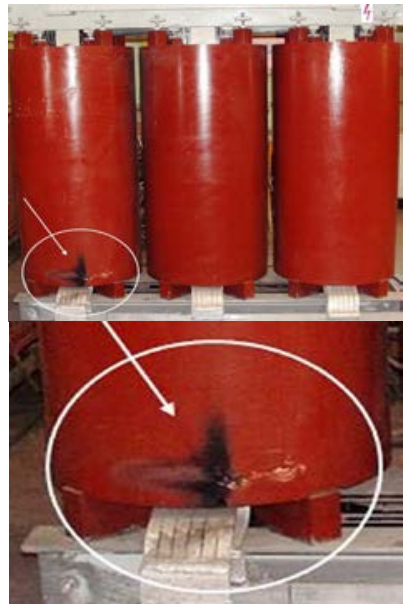

Fig.3. Analysed power transformer with defect of the coil of phase A.

\section{EXPERIMENTAL ANALYSIS OF THE POWER TRANSFORMER 22 / $0.4 \mathrm{KV}$}

On the basis of theoretical analyses of effects of short circuit, there were selected individual diagnostic and measurement methods for measurements on a power transformer $22 \mathrm{kV} / 0.4 \mathrm{kV}$ with defect on the high-voltage phase - coil A (Fig.3.).

Important task was to compare measured curves of single transformer winding and the sensitivity of the two diagnostic methods - high-frequency method SFRA (Sweep
Frequency Response Analysis) and the method of the time analysis of high voltage impulse by impact test. Frequency and time method (SFRA and impact test) can determine the frequency or time response of characteristic quantities of affected by impedance and phase of transformer.

There is no need of changing of construction of the measured machine for both diagnostic techniques. They are also analyzed for disconnected transformer [24].

\section{MEASUREMENT OF THE TRANSFORMER USING FREQUENCY METHOD}

The power transformer diagnostics set up uses the frequency scale from $20 \mathrm{~Hz}$ to $10 \mathrm{MHz}$ at source voltage $0.2-20 \mathrm{Vpp}$, and output impedance $50 \Omega$ using the Megger FRAX 150, (Fig.4.).

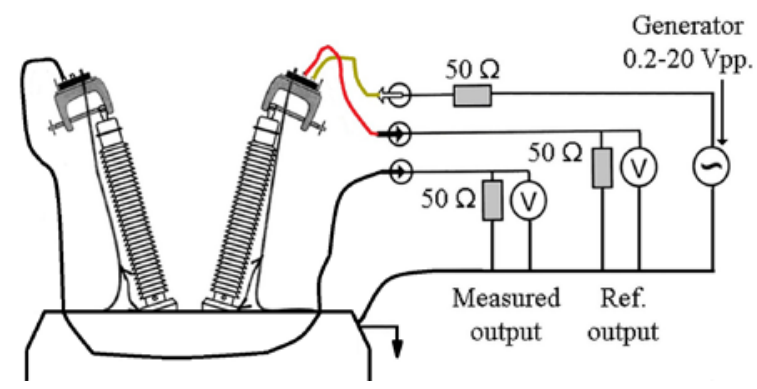

Fig.4. SFRA measurement connection using the Megger FRAX.

Mentioned analyzer can be used for magnetic core defects and detecting winding shifts of power transformers. The parameters of device are following: sampling rate $100 \mathrm{MS} / \mathrm{s}$, absolute accuracy $\pm 0.5 \mathrm{~dB}$ for dynamic range -130 to $+20 \mathrm{~dB}$. The analyses were carried out for no-load and short-circuit states.

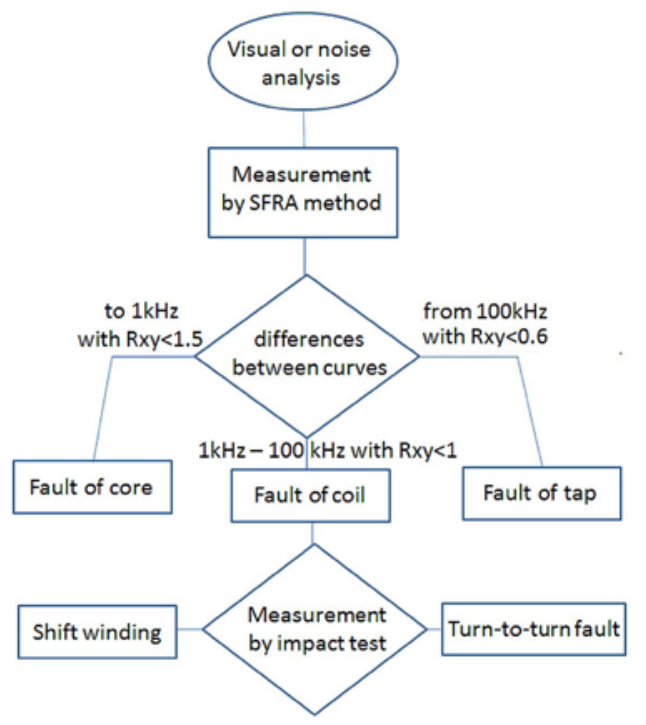

Fig.5. Block diagram of measurements of power transformer.

For low frequencies (up to $1 \mathrm{kHz}$ ) measured curves were good visible. For frequencies $(1 \mathrm{kHz}$ to $100 \mathrm{kHz}$ ) problems related to shift of windings turn-to-turn fault occurred [25]. 
For higher frequencies $(>100 \mathrm{kHz})$ the faults related to short-circuit forces may appear.

The process of fault analysis on the transformer by measurement of the SFRA method with impact test is shown in Fig.5. Differences between measured frequency curves are analyzed by value of relative factor $R_{\mathrm{xy}}$. This analysis is based on calculation of normalization factor covariance using equations (1), (2) and (3).

The short-circuit test detected winding state of the transformer. It showed deformation of internal winding. It also showed its shift as an activity of short-circuit. The impedance depending on frequency for short-circuit and noload states was presented in Fig.6.

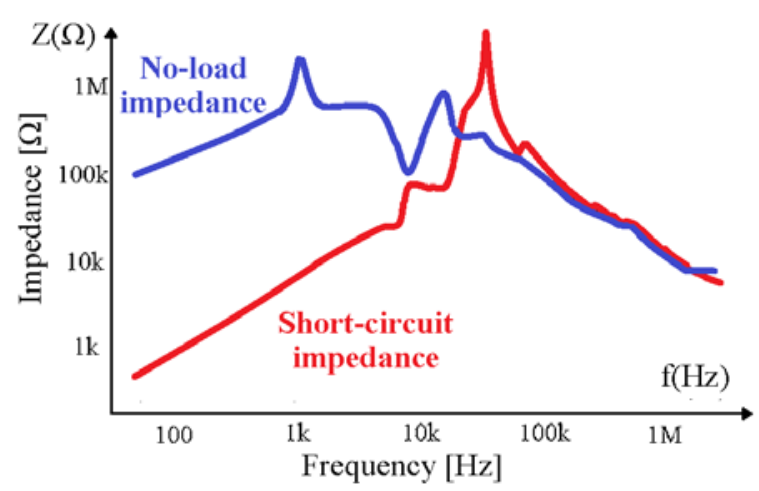

Fig.6. Impedance depending on frequency for short-circuit and no-load states.

Impedance depending on frequency of three windings of the power transformer of no-load test is depicted in Fig.7. In the Fig.7. we can see deformation of the coil A. This deformation occurred in the range of $1-10 \mathrm{kHz}$. Different values of B-C impedance mean damage of coil A for star connected transformer.

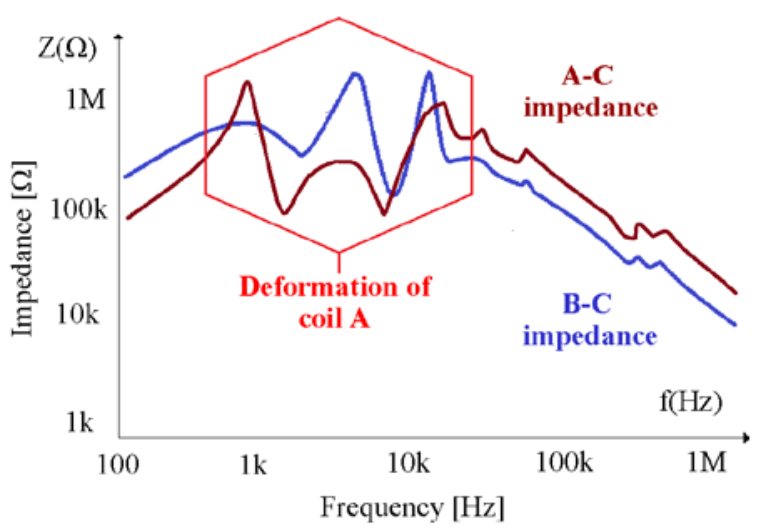

Fig.7. Impedance depending on frequency of the power transformer of no-load state.

Relative factor $R_{\mathrm{xy}}$ was used for analyses of differences between analyzed states.

For the analysis the authors used the equations (1), (2) and (3): Computation of the two compared standard variances is following:

$$
D_{x}=\sum_{K=0}^{N-1}\left[X(k)-\frac{1}{N} \sum_{K=0}^{N-1} X(k)\right]^{2} \quad D_{Y}=\frac{1}{N} \sum_{K=0}^{N-1}\left[Y(k)-\frac{1}{N} \sum_{K=0}^{N-1} Y(k)\right]^{2}
$$

where $X(k)$ and $Y(k)$ are values of curves of analysed phase connection A-C and B-C, $N$ is the number points.

Computation of the two compared covariances:

$$
C_{X Y}=\frac{1}{N} \sum_{K=0}^{N-1}\left[X(k)-\frac{1}{N} \sum_{K=0}^{N-1} X(k)\right]^{2} \cdot\left[Y(k)-\frac{1}{N} \sum_{K=0}^{N-1} Y(k)\right]^{2}
$$

For computation of two analyzed states the authors used Normalization factor of covariance.

$$
R_{X Y}=\frac{C_{X Y}}{\sqrt{D_{X} D_{Y}}}
$$

In the frequency range from $1 \mathrm{kHz}$ to $100 \mathrm{kHz}$, the value of $R_{\mathrm{xy}}$ was equal to 0.35 for no-load state. Magnitude depending on frequency for winding-phase A-C and B-C was depicted (Fig.8.).

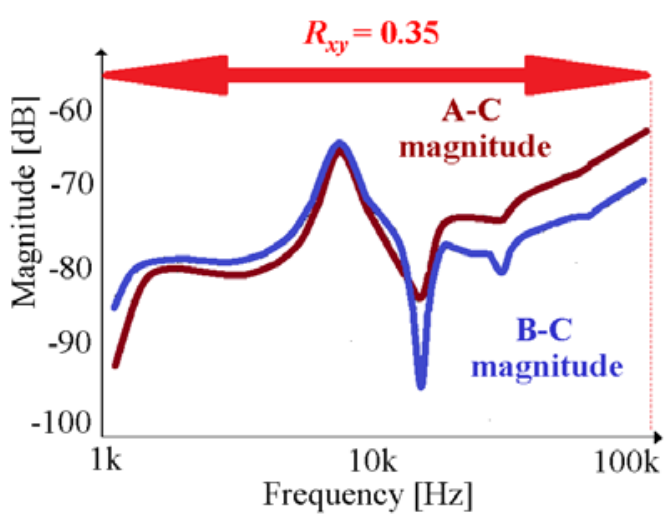

Fig.8. Magnitude depending on frequency for winding-phase A-C and B-C.

Analysis (Fig.8.) showed deformation anomaly due to short-circuit of the transformer. Damage to the power transformer is the result of damage of the phase coil A (visual damage in the Fig.3.).

\section{TIME ANALYSIS OF THE TRANSFORMER}

Time method using the impact test is often used for analysis of the insulation between coils. It is also used for detection of the attenuated winding sections of electrical machines (also transformers). This method allows us to verify early states of the coil faults. Short-time voltage pulses are used for the winding in order to form a voltage gradient across the coil of the winding. The coil dampens oscillations through transient sinus form at the time intervals among pulses. Each transformer winding has unique character of response. It can be analyzed by oscilloscope. Wave form is influenced by transient circuit depending on the winding inductance and inside capacity of the pulse generator. A diagram for the impact test method of threewinding power transformer is presented in Fig.9. 


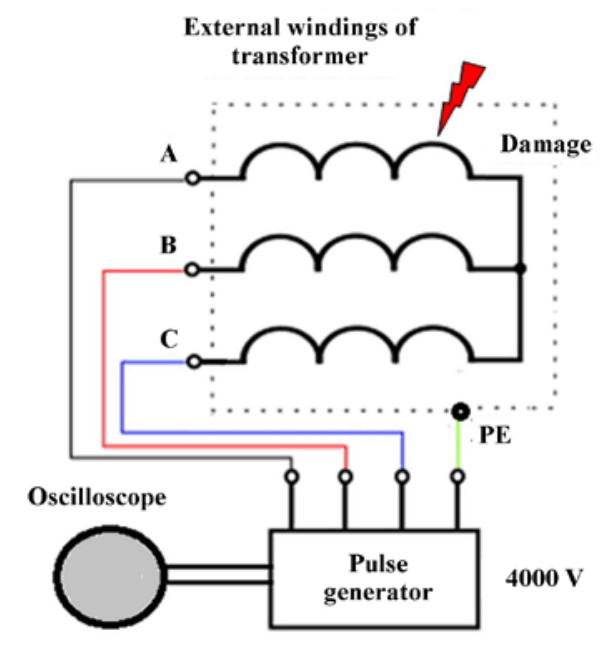

Fig.9. A diagram for the impact test method of three-winding power transformer.

Voltage of coils A and B depending on time was shown in Fig.10. It compares time curves of pulse test measurement of the transformer.

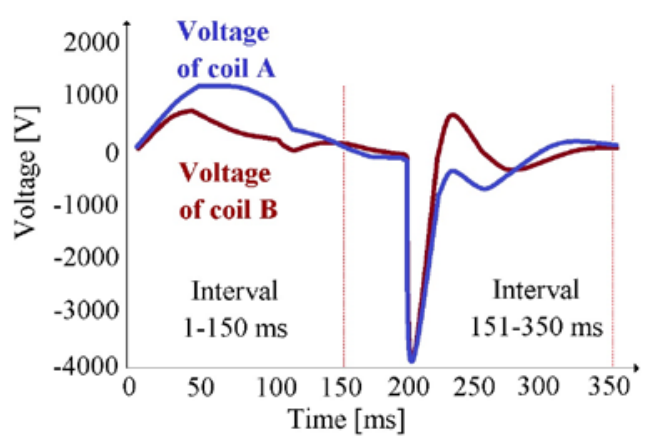

Fig.10. Analysis and comparison of transformer coils $\mathrm{A}$ and $\mathrm{B}$ using impact test.

The differences between voltage of two coils can be noticed in the range of 0-350 ms. Measurement was carried out using test of two coils. Phase of coil A is influenced by short-circuit. Phase of coil B is well visibly. The decrease of amplitude at the interval 2 (151-350 ms) is caused by change of the resistance and capacitance. It was caused by damaged insulation of coil A. State of the transformer windings can be detected if we know single curves overlap (with similar fault-free curve). Mutually shifted dependents indicate the permanent damage of one coil. Next it analyses time and amplitude differences between states. Two impulses were analyzed for two intervals. The values of amplitude coefficient related to respective ratio at time intervals were showed in Fig.11. For pairs of coils A-B and A-C at interval $0-150 \mathrm{~ms}$, the maximum value of ratio is equal to 5.47. At time interval $150-350 \mathrm{~ms}$, the maximum of ratio is equal to 8.11. The lower value of amplitude was for pair of fault-free coils B-C. The short-circuit as well as permanent deformation of coils A-C had higher value of amplitude.

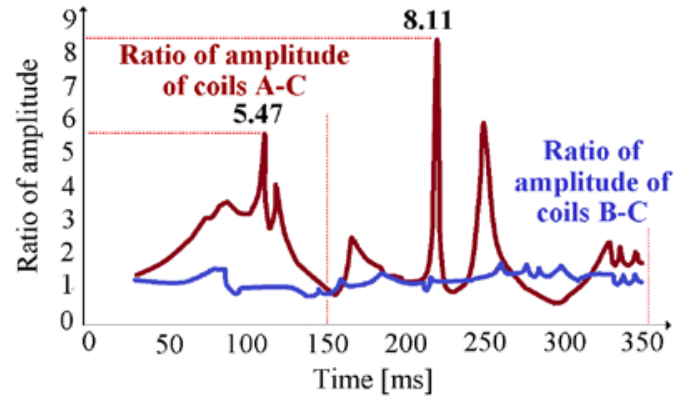

Fig.11. Ratio of amplitude of analyzed coils A-C, B-C of the transformer.

\section{CONCLUSIONS}

In the paper the authors showed the importance of knowledge about theoretical and experimental analysis of the effect of short-circuit forces. Measurements of transformer were carried out in high-voltage laboratory. The analyzed short-circuit forces caused non-reversible deformation of the winding of the power transformer. The proposed analyses showed that the effects of short-circuit current need proper diagnostic and measuring methods. Analyzed state of the transformer was dangerous for operation. Coils of transformer windings were diagnosed by means of the SFRA method and time impact test. The analyzed methods had a significant sensitivity for small deformation of coil. The proposed methods allowed us to analyze short-circuit of the coil of the transformer winding. The advantage of analyzed methods is that they can also detect the fault area in the transformer or its winding.

Fault diagnosis measuring methods should be developed to increase the reliability of electrical equipment. The proposed approach can be used for other types of transformers. Moreover, the presented techniques have potential application for fault diagnosis of electrical equipment such as: transformers and electrical machines.

In the future, the authors will analyze the effects of other short-circuit currents. The authors will also measure dielectric parameters of transformers. It would be also a good idea to analyze moisture of the insulating paper and the conductivity of the oil transformer.

\section{ACKNOWLEDGMENT}

Article was financed by the Ministry of Education of Slovak Republic, the Grant Agency VEGA under contract No. 1/0602/17.

\section{REFERENCES}

[1] Hrabovcova, V., Rafajdus, P., Franko, M., Hudák, M. (2009). Measuring and Modelling of Electrical Machines. Žilina, Slovakia: EDIS. ISBN 978-80-8070924-2. (in Slovak)

[2] Wang, T., He, Y.G., Luo, Q.W., Deng, F.M., Zhang, C.L. (2017). Self-powered RFID sensor tag for fault diagnosis and prognosis of transformer winding. IEEE Sensors Journal, 17 (19), 6418-6430. 
[3] Islam, M.M., Lee, G., Hettiwatte, S.N. (2017). A nearest neighbour clustering approach for incipient fault diagnosis of power transformers. Electrical Engineering, 99 (3), 1109-1119.

[4] Zhang, Y.Y., Wei, H., Liao, R.J., Wang, Y.Y., Yang, L.J., Yan, C.Y. (2017). A new support vector machine model based on improved imperialist competitive algorithm for fault diagnosis of oil-immersed transformers. Journal of Electrical Engineering \& Technology, 12 (2), 830-839.

[5] Peimankar, A., Weddell, S.J., Jalal, T., Lapthorn, A.C. (2017). Evolutionary multi-objective fault diagnosis of power transformers. Swarm and Evolutionary Computation, 36, 2017, 62-75.

[6] Ding, Y., Liu, Q. (2017). Data-driven fault diagnosis method for power transformers using modified Kriging model. Mathematical Problems in Engineering, 2017, art. ID 3068548.

[7] Wei, C.H., Long, H., Yan, L. (2017). Investigate transformer fault diagnosis performance of dissolved gas analysis with measurement error. Electric Power Components and Systems, 45 (8), 894-904.

[8] Yang, Q., Su, P.Y., Chen, Y. (2017). Comparison of impulse wave and sweep frequency response analysis methods for diagnosis of transformer winding faults. Energies, 10 (4), art. no. 431.

[9] Li, W.L., Liu, W.J., Wu, W., Zhang, X.B., Gao, Z.H., $\mathrm{Wu}$, X.H. (2016). Fault diagnosis of star-connected auto-transformer based 24-pulse rectifier. Measurement, 91, 360-370.

[10] Ballal, M.S., Suryawanshi, H.M., Mishra, M.K., Chaudhari, B.N. (2016). Interturn faults detection of transformers by diagnosis of neutral current. IEEE Transactions on Power Delivery, 31 (3), 1096-1105.

[11] Dai, C.X., Liu, Z.G., Hu, K.T., Huang, K. (2016). Fault diagnosis approach of traction transformers in high-speed railway combining kernel principal component analysis with random forest. IET Electrical Systems in Transportation, 6 (3), 202-206.

[12] Rigatos, G., Siano, P. (2016). Power transformers' condition monitoring using neural modeling and the local statistical approach to fault diagnosis. International Journal of Electrical Power \& Energy Systems, 80, 150-159.

[13] Illias, H.A., Chai, X.R., Abu Bakar, A. (2016). Hybrid modified evolutionary particle swarm optimisationtime varying acceleration coefficient-artificial neural network for power transformer fault diagnosis. Measurement, 90, 94-102.

[14] Mejia-Barron, A., Valtierra-Rodriguez, M., GranadosLieberman, D., Olivares-Galvan, J.C., Escarela-Perez, R. (2018). The application of EMD-based methods for diagnosis of winding faults in a transformer using transient and steady state currents. Measurement, 117, 371-379.
[15] Wang, C., Zhang, Y.G. (2015). Fault correspondence analysis in complex electric power systems. Advances in Electrical and Computer Engineering, 15 (1), 1116.

[16] Li, Z.X., Jiang, Y., Hu, C.Q., Peng, Z.X. (2017). Difference equation based empirical mode decomposition with application to separation enhancement of multi-fault vibration signals. Journal of Difference Equations and Applications, 23 (1-2), 457-467.

[17] Li, Z.X., Jiang, Y., Hu, C., Peng, Z. (2016). Recent progress on decoupling diagnosis of hybrid failures in gear transmission systems using vibration sensor signal: A review. Measurement, 90, 4-19.

[18] Glowacz, A., Glowacz, W., Glowacz, Z. (2015). Recognition of armature current of DC generator depending on rotor speed using FFT, MSAF-1 and LDA. Eksploatacja i Niezawodnosc-Maintenance and Reliability, 17 (1), 64-69.

[19] Brandt, M., Kascak, S. (2016). Failure identification of induction motor using SFRA method. In 2016 ELEKTRO: $11^{\text {th }}$ International Conference, 16-18 May 2016. IEEE, 269-272.

[20] Petras, J., Kurimsky, J., Balogh, J., Cimbala, R., Dzmura, J., Dolnik, B., Kolcunova, I. (2016). Thermally stimulated acoustic energy shift in transformer oil. Acta Acoustica United with Acoustica, 102 (1), 16-22.

[21] Brandt, M. (2016). Identification failure of 3 MVA furnace transformer. In Diagnostic of Electrical Machines and Insulating Systems in Electrical Engineering (DEMISEE), 20-22 June 2016. IEEE, 610.

[22] Chen, W.G., Liu, J., Wang, Y.Y., Liang, L.M., Zhao, J.B., Yue, Y.F. (2008). The measuring method for internal temperature of power transformer based on FBG sensors. In 2008 International Conference on High Voltage Engineering and Application (ICHVE), 9-12 November 2008. IEEE, 672- 676.

[23] Werelius, P., Ohlen, M., Adeen, L., Brynjebo, E. (2007). Measurement considerations using SFRA for condition assessment of Power Transformers. In 2008 International Conference on Condition Monitoring and Diagnosis, 21-24 April 2008. IEEE, 898-901.

[24] Chitaliya, G.H., Joshi, S.K. (2013). Finite Element Method for designing and analysis of the transformer A retrospective. In International Conference on Recent Trends in Power, Control and Instrumentation Engineering (PCIE 2013). Association of Computer Electronics and Electrical Engineers, 54-58.

[25] Heathcote, M.J. (2007). The J \& P Transformer Book, $13^{\text {th }}$ Edition. Elsevier, ISBN 978-0-7506-8164-3.

Received April 17, 2018 Accepted July 10, 2018 